\title{
High-Frequency Stimulation of the Anterior Subthalamic Nucleus Reduces Stereotyped Behaviors in Primates
}

\author{
Nicolas Baup, ${ }^{1,2,3 \star}$ David Grabli, ${ }^{2,3,4 \star}$ Carine Karachi, ${ }^{2,3,4 \star}$ Stéphanie Mounayar, ${ }^{2,3}$ Chantal François, ${ }^{2,3}$ Jérôme Yelnik, ${ }^{2,3}$ \\ Jean Féger, ${ }^{2,3}$ and Léon Tremblay ${ }^{5}$ \\ ${ }^{1}$ Département de Psychiatrie, Centre Hospitalier Saint Anne, Paris F-75014, France, ${ }^{2}$ Département de Neurologie et de Thérapeutique Expérimentale \\ INSERM, UMR S679, ${ }^{3}$ Université Pierre et Marie Curie Paris 6, UMR S679, and ${ }^{4}$ Assistance Publique-Hôpitaux de Paris, Groupe Pitié-Salpêtrière, Paris \\ F-75013, France, and Institut des Neurosciences Cognitives, UMR 5229, Centre National de la Recherche Scientifique-Université de Lyon 1, Bron F-69675, \\ France
}

Growing evidence shows that dysfunction of the limbic basal ganglia (BG) network is implicated in repetitive behaviors, such as obsessive compulsive disorder (OCD) and Tourette's syndrome (TS), in humans. Because deep brain stimulation (DBS) of the posterior subthalamic nucleus (STN), which modulates the sensorimotor BG network, is beneficial in movement disorders, stimulation of the anterior, limbic STN might improve intractable behavioral disorders. We therefore evaluated the effect of anterior STN stimulation on the repetitive behaviors induced in two monkeys after bicuculline-induced dysfunction of the limbic external globus pallidus. DBS in the anterior STN dramatically reduced the stereotypies, but had no effect on the performance of a simple food retrieval task. Stimulations outside the STN were less effective in reducing the stereotypies. Electrode trajectories, reconstructed postmortem, confirmed that the effective contacts were in the anterior STN. DBS in the limbic STN might therefore provide relief from the severe stereotyped behaviors observed in OCD and TS.

Key words: basal ganglia; subthalamic nucleus; stimulation; globus pallidus; behavior; bicuculline; primate

\section{Introduction}

Deep brain stimulation (DBS) has proved to be a powerful tool for the treatment of Parkinson's disease (Limousin et al., 1995; Deuschl et al., 2006), essential tremor (Schuurman et al., 2000), and dystonia (Vidailhet et al., 2005; Kupsch et al., 2006). The optimal targets in these movement disorders, which included the cerebellar territory of the thalamus, the internal globus pallidus (GPi), and the subthalamic nucleus (STN), were selected on the basis of studies in primate models (Bergman et al., 1990, Benazzouz et al., 1993) or in accordance with past surgical experience with brain lesions. There is increasing evidence that a dysfunction within the limbic basal ganglia network is central to stereotyped behavioral disorders characterized by repetition of a set of behavioral patterns, such as Tourette syndrome (TS) (Vandewalle et al., 1999; Houeto et al., 2005) and obsessive compulsive disorder (OCD) (Aouizerate et al., 2004a). We showed previously that bicuculline microinjections in the limbic and associative parts of the external globus pallidus (GPe) in monkeys induced stereotypy and attention deficit or hyperactivity, respectively (Grabli et

\footnotetext{
Received May 23, 2008; accepted June 11, 2008.

This work was supported by grants from the Tourette Syndrome Association and Fondation de l'Avenir, the Fondation pour la Recherche Médicale (N.B.), the Assistance Publique des Hôpitaux de Paris (D.G.), and the Association Française du Syndrome de Gilles de la Tourette (C.K., S.M.).

*N.B., D.G., and C.K. contributed equally to this work.

Correspondence should be addressed to Léon Tremblay, Institut des Neurosciences Cognitives, UMR5229, Centre National de la Recherche Scientifique-Université de Lyon 1, 67 Boulevard Pinel, Bron F-69675, France. E-mail: leon.tremblay@isc.cnrs.fr.

DOI:10.1523/JNEUROSCI.2384-08.2008

Copyright $\odot 2008$ Society for Neuroscience $\quad 0270-6474 / 08 / 288785-04 \$ 15.00 / 0$
}

al., 2004), in accordance with the cognitive and behavioral functions attributed to the associative and limbic basal ganglia circuits (Alexander et al., 1986).

This primate model offers the opportunity to test whether modulation of the limbic STN by DBS can reduce repetitive behaviors. We have therefore investigated the effect of DBS in the anterior STN in this primate model of behavioral disorder. The anterior STN was chosen as the DBS target for three reasons. First, the anterior part of the STN is occupied by the limbic anatomofunctional territory (Karachi et al., 2005). Second, stimulation of this structure affects the neuronal activity of the GPi and SNr, the two outputs nuclei of the BG involved in the stereotypy (François et al., 2004). Third, the obsessive compulsive symptoms in two patients with Parkinson's disease and a severe OCD were improved by STN DBS (Mallet et al., 2002).

\section{Materials and Methods}

Experiments were conducted on two male African Green monkeys (Cercopithecus aethiops sabaeus) aged between 4 and 6 years. The monkeys were treated in accordance with National Institutes of Health guidelines (1996) and the recommendations of the EEC (86/609) and the French National Committee (87/848).

Surgical procedures. The recording chamber was implanted during a first surgical procedure to allow bicuculline microinjections in the GPe as described previously (Grabli et al., 2004). During a second surgical procedure under general anesthesia, 1.2-mm-diameter quadripolar stimulating leads (DIXI Medical) with four cylindrical electrode contacts (1.0 $\mathrm{mm}$ of length spaced by $0.5 \mathrm{~mm}$ and numbered as contact 0 , at the tip, to 3 ) were stereotaxically implanted into the left anterior STN of the monkeys using intraoperative microelectrode single unit recording (see Fig. 
1A). The leads were connected to an external pulse generator (WPI) through a connector permanently fixed to the skull. Unipolar stimulation was applied with fixed frequency and pulse width ( $130 \mathrm{~Hz}$ and $60 \mathrm{~ms}$, respectively) but variable voltage $(0-3 \mathrm{~V})$.

Behavioral analysis. Monkeys were acclimated to the experimental conditions and learned the simple food retrieval task during 3 months before the implantation of the recording chamber. After each surgical procedure, the animals were allowed to recover. One of the four following types of experimental sessions were conduced daily and randomly alternated: (1) control sessions without microinjections and without DBS, (2) sessions with microinjections of bicuculline in the limbic GPe, (3) sessions with stimulation alone, and (4) sessions with microinjections followed by anterior STN stimulation. Sessions with stimulation consisted in a random alternation of ON stimulation periods and OFF stimulation periods. Spontaneous behaviors and task execution were observed and recorded using a video system. The frequency and the duration of the behaviors or abnormal movements were quantified off-line from the after consensus of four experimenters (N.B., D.G., C.K., and S.M.) blinded to the condition. The duration of the stereotypies was evaluated by $3 \mathrm{~min}$ segments in each experimental session.

Simple food-retrieval task. For the simple food-retrieval task (Grabli et al., 2004), the monkeys were conditioned to retrieve pieces of food from a two parts (left and right) board with the left and right hand respectively. The monkey had to perform six to eight blocks of this task in each experimental condition and the time needed to empty each part of the board was scored. The data were pooled for each monkey according to the type of session and to the condition (control periods, postinjection OFF DBS periods, and postinjection ON DBS periods).

Statistical analysis. Behaviors were quantified by segment of 3 min over the entire experimental session. Each condition lasted 12-21 min corresponding to four to six periods of $3 \mathrm{~min}$. For analysis of the effect of DBS on spontaneous behaviors (sessions without injection), the mean duration of behaviors during stimulation periods were compared alternately with the mean duration of behaviors during the previous or the succeeding periods without stimulation obtained the same day. For the analysis of DBS effect on stereotypies induced by bicuculline injection, the experimental sessions were divided as follows: (1) "control periods" corresponding to preinjection periods without induction of stereotypy, (2) "OFF stimulation periods" corresponding to postinjection periods with induction of stereotypies, and (3) "ON stimulation periods" corresponding to postinjection periods with induction of stereotypies and stimulation applied. The effect of injection was defined as the difference of the mean duration of stereotypies between the periods 1 and 2 . The effect of stimulation on stereotypies was defined as the difference of the mean duration of stereotypies between the periods 2 and 3. The results were compared using the Mann-Whitney test. Finally, task data under the different conditions were compared with the Mann-Whitney test. Results of all the analyses were considered significant at $p<0.05$.

Histological procedures. After the experiments, the monkeys were killed with an overdose of anesthetic and perfused transcardially with $5 \mathrm{~L}$ of $4 \%$ paraformaldehyde (François et al., 2004). The electrode was removed and the brain was extracted and immersed in $20 \%$ sucrose in PBS for $2 \mathrm{~d}$, then frozen and cut into $50-\mu \mathrm{m}$-thick frontal sections perpendicular to the intercommissural plane (François et al., 2004). The perimeter of the
STN and the traces of the electrodes (see Fig. $1 B$ ) were drawn from serial sections (see Fig. $1 C, C^{\prime}$ ), digitized with a dedicated software and reconstructed in a three dimensional space (see Fig. $1 D-E^{\prime}$ ). The section corresponding to the center of each contact was determined by its distance from the tip of the electrode. The sensorimotor, associative and limbic territories of the GPe were defined by calbindin immunoreactivity (François et al., 1994). Microinjection sites and trajectories of the electrodes were reconstructed from cresyl violet-stained sections and compared with the borders of the functional territories of the GPe (see Fig. 2A, B).

\section{Results}

No increase in stereotypies has been found between the beginning and the end of the 3 month training period. No change in the spontaneous behavior (control sessions) and in task execution was observed after the implantation of the electrode in the monkeys. No lesions caused by electrode implantation were observed on histological sections. The most ventral contact (contact 0 ) of the quadripolar electrode was located in the anterior tip of the STN in both monkeys but was more anterior and ventral in monkey B than in monkey A (Fig. 1). Contact 1 was located more dorsally in the zona incerta just above the STN. Contacts 2 and 3 were located in the ventral and dorsal part of the motor thalamus.

The effect of DBS on movement, spontaneous behavior and task performance was first studied as a function of current inten- 
A
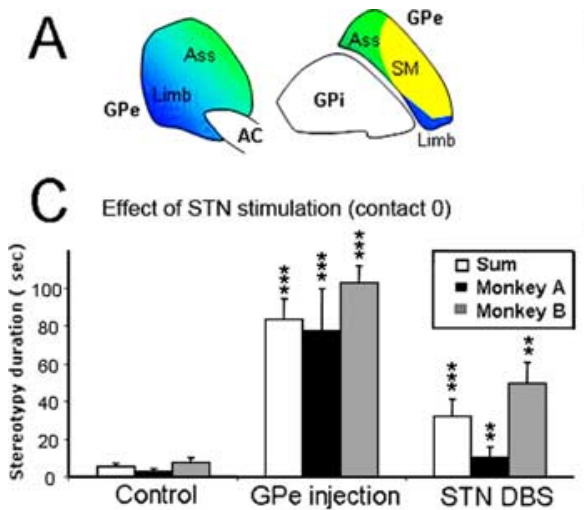

D

Effect of individual STN DBS challenges

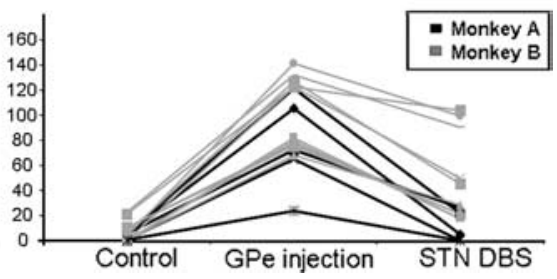

Figure 2. A, Representation of the associative (Ass), limbic (Limb), and sensorimotor (SM) territories of the GPe illustrated in green, blue, and yellow, respectively. $\boldsymbol{B}$, Localization of the injection sites in the anterior part of GPe in monkeys A (triangles) and $B$ (circles). C, Mean total duration of behaviors by periods of $180 \mathrm{~s}$ for DBS challenges at contact 0 . Values are given for monkey $A$ (black bars), B (gray bars), and both (white bars). The error bars show the SEM. ${ }^{* *} p<0.01$; ${ }^{* * *} p<0.001$. D, Results of individual stimulation challenges at contact 0 . Duration of stereotypies by periods of $180 \mathrm{~s}$ is given in three conditions: control, injection alone, and injection with stimulation for monkey A (black lines) and monkey B (gray lines).

sity. For both monkeys, stimulation at all sites induced fixed dystonia in the contralateral limb, at current intensity $>1.5 \mathrm{~V}$ for contact 1 and $>3 \mathrm{~V}$ for contacts 0,2 , and 3 . Subsequent experiments were therefore performed below a threshold of $2.5 \mathrm{~V}$ for contacts 0,2 and 3 . The particularly low threshold of contact 1 excluded this contact for the rest of the experiment for both monkeys. Under the thresholds for abnormal movements, the impact of the DBS was assessed on spontaneous behavior in the primate chair. The spontaneous behavior of monkey A mostly consisted in resting. No increase of behavioral activity was observed when stimulation was applied at contacts 0,2 , and 3 . Conversely, monkey B displayed a wide range of behaviors including a spontaneous tendency to lick its fingers during control sessions. During stimulation at contact 0 , this spontaneous behavior was reduced by nearly $100 \%$, whereas there was no effect of stimulation through contacts 2 and 3 for monkey B. There was no additional effect on task execution and the retrieval time did not change.

We then analyzed the effects of anterior STN DBS on stereotypies induced by microinjections of bicuculline into the limbic GPe. All of the microinjections induced the same behavioral effect with slightly different intensities as described previously (Grabli et al., 2004). Stereotypies were induced by 15 microinjections of bicuculline (seven and eight injections in monkey $\mathrm{A}$ and $\mathrm{B}$, respectively) into the limbic GPe at seven different sites. The localization of these injection sites, the behavioral effect induced and a schematic representation of the functional territories of the GPe are shown in Figure 2. Stereotypies obtained in both animals were comparable with those described previously (Grabli et al., 2004). They consisted of licking or biting the fingers or nails of both hands and began 3-12 min after the injection of bicuculline. This behavior was intense and repeated frequently during periods of $83.1 \pm 11.3 \mathrm{~s}$ vs $5.5 \pm 1.8 \mathrm{~s}$ during the control session, for a total observation time of $180 \mathrm{~s}$ (Fig. 2), and remained stable for $>50$ $\mathrm{min}$. The type of behavior, its intensity, latency and duration were similar after each injection.

Stimulation applied at contact 0 significantly reduced stereotypies in a reproducible manner in both monkeys. The duration of the stereotypies was drastically reduced in monkey A, (decrease of $88.2 \pm 15.4 \%$ ) and slightly less in monkey B (decrease of $50.4 \pm 18.5)$. In monkey B, the reduction was similar at $2.0 \mathrm{~V}$ (reduction of $55.3 \pm 18.1 \%$ ) and $2.5 \mathrm{~V}$ (reduction of $45.5 \pm$

\section{Discussion}

This study provides evidence that DBS of the anterior STN of monkeys can dramatically reduce stereotypies induced by an ipsilateral local dysfunction of the limbic GPe. The STN is therefore a promising target for DBS treatment of behavioral disorders as OCD and TS.

The significant reduction of induced stereotypies after DBS of the anterior part of the STN was consistent. This reduction exceeded $80 \%$ for monkey A and $50 \%$ for monkey B. The effects were highly reproducible in each monkey and between the monkeys, whatever the microinjection site in the anterior GPe. Importantly, there was no concomitant effect on the normal range of behaviors of the monkeys (ability to move, take attention or motivation to direct their actions to eat food). Electrode implantation did not induce motor side effects such as the hemiballism that was previously reported after STN lesion or dysfunction (Hammond et al., 1979; Crossman et al., 1984). This may be explained by the anteromedial location of the electrode in the limbic territory of the STN, rather than in the posterolateral sensorimotor part of the nucleus.

These results demonstrate in two normal monkeys that DBS of the anterior STN is safe and does not produce adverse effects. The efficacy of anterior STN simulation on pallidal-induced stereotypies is consistent with the finding that the pallidal sites where stereotypied behaviors were elicited are connected to the limbic territory of the anterior STN (François et al., 2004; Karachi et al., 2005). The transposition of these results to the surgical practice in human must however be cautious. First, even if our model reproduces symptoms that are similar to those of OCD or TS, there is no evidence in favor of a primary dysfunction in the limbic GPe in these disorders. Second, because the effect of bicuculline is acute, we tested stimulation over periods of 12-21 min, which is sufficient to demonstrate its efficacy for suppressing stereotypies but not to test it over periods of several months as it would be applied in human.

The choice of a limbic target in human is supported by previous studies that report successful surgical treatment of untreatable OCD and TS using DBS in various other brain areas, including the anterior limb of internal capsule (Abelson et al., 2005; Flaherty et al., 2005; Greenberg et al., 2006), the ventral caudate nucleus (Aouizerate et al., 2004b, 2005), the limbic GPi (Died- 
erich et al., 2005; Houeto et al., 2005; Shahed et al., 2007) or the centromedian/parafascicularis nucleus (Visser-Vandewalle et al., 2003; Houeto et al., 2005; Ackermans et al., 2006; Servello et al., 2007). Our results in monkeys are also in line with recent surgical experience acquired in Parkinson's disease suggesting that DBS of the STN can produce unexpected behavioral processes (Krack et al., 2001; Houeto et al., 2006; Mallet et al., 2007) but also improve OCD symptoms associated with PD (Mallet et al., 2002). The advantage of the STN target is the small size of this nucleus which would allow to extend stimulation to the adjacent associative and motor territories that could also be involved in the motor and cognitive aspects of TS and OCD symptomatology.

Despite the limitations of the small number of monkeys and the acute DBS setting, this study provides a strong evidence of the efficacy of anterior STN-DBS for the treatment of abnormal behaviors in the monkey, and an additional argument in favor of its use in severe intractable TS or OCD in humans. Additional studies should now be performed to confirm these findings in additional monkeys and under chronic stimulation settings.

\section{References}

Abelson JL, Curtis GC, Sagher O, Albucher RC, Harrigan M, Taylor SF, Martis B, Giordani B (2005) Deep brain stimulation for refractory obsessivecompulsive disorder. Biol Psychiatry 57:510-516.

Ackermans L, Temel Y, Cath D, van der Linden C, Bruggeman R, Kleijer M, Nederveen P, Schruers K, Colle H, Tijssen MA, Visser-Vandewalle V (2006) Deep brain stimulation in Tourette's syndrome: two targets? Mov Disord 21:709-713.

Alexander GE, DeLong MR, Strick PL (1986) Parallel organization of functionally segregated circuits linking basal ganglia and cortex. Annu Rev Neurosci 9:357-381.

Aouizerate B, Guehl D, Cuny E, Rougier A, Bioulac B, Tignol J, Burbaud P (2004a) Pathophysiology of obsessive-compulsive disorder: a necessary link between phenomenology, neuropsychology, imagery and physiology. Prog Neurobiol 72:195-221.

Aouizerate B, Cuny E, Martin-Guehl C, Guehl D, Amieva H, Benazzouz A, Fabrigoule C, Allard M, Rougier A, Bioulac B, Tignol J, Burbaud P (2004b) Deep brain stimulation of the ventral caudate nucleus in the treatment of obsessive-compulsive disorder and major depression. Case report. J Neurosurg 101:682-686.

Aouizerate B, Martin-Guehl C, Cuny E, Guehl D, Amieva H, Benazzouz A, Fabrigoule C, Bioulac B, Tignol J, Burbaud P (2005) Deep brain stimulation for OCD and major depression. Am J Psychiatry 162:2192.

Benazzouz A, Gross C, Féger J, Boraud T, Bioulac B (1993) Reversal of rigidity and improvement in motor performance by subthalamic highfrequency stimulation in MPTP-treated monkeys. Eur J Neurosci 5:382-389.

Bergman H, Wichmann T, DeLong MR (1990) Reversal of experimental parkinsonism by lesions of the subthalamic nucleus. Science 249:1436-1438.

Crossman AR, Sambrook MA, Jackson A (1984) Experimental hemichorea/ hemiballismus in the monkey. Studies on the intracerebral site of action in a drug-induced dyskinesia. Brain 107:579-596.

Deuschl G, Schade-Brittinger C, Krack P, Volkmann J, Schäfer H, Bötzel K, Daniels C, Deutschländer A, Dillmann U, Eisner W, Gruber D, Hamel W, Herzog J, Hilker R, Klebe S, Kloss M, Koy J, Krause M, Kupsch A, Lorenz D, et al. (2006) A randomized trial of deep-brain stimulation for Parkinson's disease. N Engl J Med 355:896-908.

Diederich NJ, Kalteis K, Stamenkovic M, Pieri V, Alesch F (2005) Efficient internal pallidal stimulation in Gilles de la Tourette syndrome: a case report. Mov Disord 20:1496-1499.

Flaherty AW, Williams ZM, Amirnovin R, Kasper E, Rauch SL, Cosgrove GR, Eskandar EN (2005) Deep brain stimulation of the anterior internal capsule for the treatment of Tourette syndrome: technical case report. Neurosurgery 57:E403; discussion E403.

François C, Yelnik J, Percheron G, Tandé D (1994) Calbindin D-28k as a marker for the associative cortical territory of the striatum in macaque. Brain Res 633:331-336.
François C, Grabli D, McCairn K, Jan C, Karachi C, Hirsch EC, Féger J, Tremblay L (2004) Behavioural disorders induced by external globus pallidus dysfunction in primates II. Anatomical study. Brain 127:2055-2070

Grabli D, McCairn K, Hirsch EC, Agid Y, Féger J, François C, Tremblay L (2004) Behavioural disorders induced by external globus pallidus dysfunction in primates: I. Behavioural study. Brain 127:2039-2054.

Greenberg BD, Malone DA, Friehs GM, Rezai AR, Kubu CS, Malloy PF, Salloway SP, Okun MS, Goodman WK, Rasmussen SA (2006) Threeyear outcomes in deep brain stimulation for highly resistant obsessivecompulsive disorder. Neuropsychopharmacology 31:2384-2393.

Hammond C, Feger J, Bioulac B, Souteyrand JP (1979) Experimental hemiballism in the monkey produced by unilateral kainic acid lesion in corpus Luysii. Brain Res 171:577-580.

Houeto JL, Karachi C, Mallet L, Pillon B, Yelnik J, Mesnage V, Welter ML, Navarro S, Pelissolo A, Damier P, Pidoux B, Dormont D, Cornu P, Agid Y (2005) Tourette's syndrome and deep brain stimulation. J Neurol Neurosurg Psychiatry 76:992-995.

Houeto JL, Mallet L, Mesnage V, Tezenas du Montcel S, Béhar C, Gargiulo M, Torny F, Pelissolo A, Welter ML, Agid Y (2006) Subthalamic stimulation in Parkinson disease: behavior and social adaptation. Arch Neurol 63:1090-1095.

Karachi C, Yelnik J, Tandé D, Tremblay L, Hirsch EC, François C (2005) The pallidosubthalamic projection: an anatomical substrate for nonmotor functions of the subthalamic nucleus in primates. Mov Disord 20:172-180.

Krack P, Kumar R, Ardouin C, Dowsey PL, McVicker JM, Benabid AL, Pollak P (2001) Mirthful laughter induced by subthalamic nucleus stimulation. Mov Disord 16:867-875.

Kupsch A, Benecke R, Müller J, Trottenberg T, Schneider GH, Poewe W, Eisner W, Wolters A, Müller JU, Deuschl G, Pinsker MO, Skogseid IM, Roeste GK, Vollmer-Haase J, Brentrup A, Krause M, Tronnier V, Schnitzler A, Voges J, Nikkhah G, et al. (2006) Pallidal deep-brain stimulation in primary generalized or segmental dystonia. $\mathrm{N}$ Engl J Med 355:1978-1990.

Limousin P, Pollak P, Benazzouz A, Hoffmann D, Le Bas JF, Broussolle E, Perret JE, Benabid AL (1995) Effect of parkinsonian signs and symptoms of bilateral subthalamic nucleus stimulation. Lancet 345:91-95.

Mallet L, Mesnage V, Houeto JL, Pelissolo A, Yelnik J, Behar C, Gargiulo M, Welter ML, Bonnet AM, Pillon B, Cornu P, Dormont D, Pidoux B, Allilaire JF, Agid Y (2002) Compulsions, Parkinson's disease, and stimulation. Lancet 360:1302-1304.

Mallet L, Schüpbach M, N'Diaye K, Remy P, Bardinet E, Czernecki V, Welter ML, Pelissolo A, Ruberg M, Agid Y, Yelnik J (2007) Stimulation of subterritories of the subthalamic nucleus reveals its role in the integration of the emotional and motor aspects of behavior. Proc Natl Acad Sci USA 104:10661-10666.

Schuurman PR, Bosch DA, Bossuyt PM, Bonsel GJ, van Someren EJ, de Bie RM, Merkus MP, Speelman JD (2000) A comparison of continuous thalamic stimulation and thalamotomy for suppression of severe tremor. N Engl J Med 342:461-468.

Servello D, Porta M, Sassi M, Brambilla A, Robertson MM (2007) Deep brain stimulation in 18 patients with severe Gilles de la Tourette syndrome refractory to treatment: the surgery and stimulation. J Neurol Neurosurg Psychiatry 79:136-142.

Shahed J, Poysky J, Kenney C, Simpson R, Jankovic J (2007) GPi deep brain stimulation for Tourette syndrome improves tics and psychiatric comorbidities. Neurology 68:159-160.

Vandewalle V, van der Linden C, Groenewegen HJ, Caemaert J (1999) Stereotactic treatment of Gilles de la Tourette syndrome by high frequency stimulation of thalamus. Lancet 353:724.

Vidailhet M, Vercueil L, Houeto JL, Krystkowiak P, Benabid AL, Cornu P, Lagrange C, Tézenas du Montcel S, Dormont D, Grand S, Blond S, Detante O, Pillon B, Ardouin C, Agid Y, Destée A, Pollak P (2005) Bilateral deep-brain stimulation of the globus pallidus in primary generalized dystonia. N Engl J Med 352:459-467.

Visser-Vandewalle V, Temel Y, Boon P, Vreeling F, Colle H, Hoogland G, Groenewegen HJ, van der Linden C (2003) Chronic bilateral thalamic stimulation: a new therapeutic approach in intractable Tourette syndrome. Report of three cases. J Neurosurg 99:1094-1100. 